\title{
Influence of Popular Music on Mass Culture in Contemporary China
}

\author{
Huaming Cai
}

College of the Arts, Qiongzhou University, Sanya, 572022, China

\author{
Keywords: Popular music, Mass culture, Influence, Relationship
}

\begin{abstract}
Popular music is widely transmitted in people's daily life, which has important influence on communicability, universality and sociality of mass culture in contemporary China. Popular music gradually integrates into people's life. Listening to some happy popular music in sadness is helpful for relieving the mood. Listening to some inspirational popular music in work can encourage people to make great efforts. Listening to some easy popular music in sleepless night is helpful for sleep. According to prosperous development of mass culture in China, popular music plays an important role in our life. As one of mass culture representatives, popular music plays an important role in communication of contemporary mass culture in China.
\end{abstract}

\section{Communicability of popular music}

\section{Overview of popular music}

Popular music is also termed as public music. Generally, it refers to popular songs or instruments widely accepted by people and with lively pattern and sincere emotion. Popular music includes jazz in western music, rock, soul, rap, blue, new age and other kinds of mass popular music. Influenced by European and American popular music, Chinese popular music gradually forms its unique style. Popular music is sung by many people. Such definition is equivalent to positioning popular music on the foundation of popular music. It is incompletely correct. Although popular is one characteristic of popular music, popular music is essentially a kind of commodity music. Commodity music refers to music created for the purpose of profit. Commodity of popular music decides the fact that we cannot list those inspiring and non-commercial songs into popular music, such as March of the Volunteers and The East Is Red. However, music categories belonging to popular music but paid no attention to are excluded from popular music. Therefore, not all popular songs belong to popular music. Popular music may not be popular.

\section{Development of Chinese popular music}

Up to now, popular music has already developed for 60 years in China. Although early popular music also appeared in Taiwan and Hong Kong, popular music really having its style should trace back to Shanghai in the 1940s. In that period of time, Shanghai was the first one to accept European and American popular music. The record industry appeared. With development of the record industry, Shanghai widely transmitted European and American popular music. However, European and American movie and broadcast were also gradually introduced to the mainland from Shanghai. Li Jinhui, the founder of Chinese popular music, combined the melody of Chinese folk music with western dance music, which influenced the style of Chinese popular music. Li Jinhui used to lead the Chinese Song \& Dance Ensemble to perform in Singapore, Thailand, Hong Kong and other countries. His children songs \& dances, Drizzle and other musical works won a good reputation. Then, popular music entered the stage of rapid development. Zhou Xuan, Bai Guang, Zhao Dan and others began to create popular music. Up to now, their songs are sung by many people. From another side, this also indicates their important roles in the development course of Chinese popular music. Due to political impact in the 1930s - 1970s, development of popular music was influenced by political propaganda. As a result, popular music created in this period of time cannot represent development tendency of the whole popular music. In the 1980s, Winter Fire is one of works with personal color. Although popular music with national background (like On the Hopeful Field) also existed in this period, 
popular music started to have new development. After 1994, original popular music in the mainland was represented by rock music of He Yong and Dou Wei, campus music of Lao Lang and others and icon music of Mao Ming. After the 1990s, China learnt from Japan, South Korea, Europe and America. Although musical creation catered for the public, it lost its own style. Basically, all songs belong to hip-hop without much difference. Till in the $21^{\text {st }}$ century, a unique style appeared in China, in which Chinese style was integrated into popular music, such as Jay Chou's Qinghuaci and Leehom Wang's Zaimeibian. Chinese traditional culture was integrated into these songs. At the same time, unique music types (like Chinese Beijing opera and Kunqu Opera) were absorbed. All above statements are new development of Chinese popular music.

\section{Communication characteristics of popular music}

Popular music is loved by many audiences, which cannot be separated from its characteristics. Popular music has the following 5 characteristics:

1). Wide popularity: The most significant feature of popular music is its wide popularity. Popular music is quite popular among wide audiences. The contents of popular songs are close to the public's life and comply with the people's life interests. Moreover, song words are simple and clear, which are easily accepted by the public. Therefore, popularity is the essential feature of popular music.

2). Fluent melody and popular singing style: Popular music is characterized with smooth melody, popular singing style and not wide range. Everyone can sing popular songs. This is also a reason for the public's quick acceptance of popular music.

3). Popular music emphasizes emotional conveying and natural affection, which can quickly cause the public's resonance. Emotional conveying in popular music emphasizes conveying of singing techniques. This kind of emotional interaction and communication can quickly cause the public's resonance, just like we cannot help crying while listening to Still Have You at Least. This is our emotional interaction and emotional delivery with the singer.

4). Singing occupies the leading position. Popular music also emphasizes coordination with the instruments, but it is different from classical music and instruments. The most important factor in popular music is singing. Despite whatever form development, popular music keeps constantly developing with emphasis on singing.

\section{Communicability of mass culture}

\section{Concept of mass culture}

Mass culture refers to culture believed and accepted by most people in a certain country or region. Generally, mass culture is transmitted through newspaper, broadcast and network. It is a cultural product of the whole society. Specific definition of mass culture is shown as follows: cultural type emerging in modern metropolis, closely associated with large-scale industry and adopting advanced and global modern media for mass production and communication. It is also a pattern of fashion culture consumption existing in consumption or consumption-to-be age and led according to consumption ideology.

\section{Development of Chinese mass culture}

In China, mass culture appeared in the second half of $20^{\text {th }}$ century. With the formation of the pattern of reform and opening-up, Chinese mass culture got continuous development under the guarantee of market economy. Only in 20 years, mass culture became Trinitarian composition of mainstream official culture and elite culture in the academic world. Mass culture plays an important role in building national spirit and promoting social development. At the same time, large-scale participation of the public into construction of social culture is a cultural event involving the public's wide participation and with the largest scale. Chinese mass culture mainly includes popular novel, popular music, popular movie, fashion, advertising and other cultural patterns. This diversity of cultural work patterns also further quickened development of mass culture. In the earliest stage, 
development of Chinese mass culture can trace back to the 1980s. In 1978, the Third Plenary Session of the $1^{\text {th }}$ Central Committee of the CCP made a literature and art policy development plan about reform \& opening up and service to peasants and soldiers, promoting the development of Chinese mass culture. People's Daily took the lead to construct culture. In 1978, Careful Adjustment to the Party's Literature and Art Policies paid attention to the public education of mass culture, and changed the previous view of culture serving politics. It triggered a reflection climax in the whole academic world. Then, Deng Xiaoping pointed out the spirit of "literature and art serving the people and the society" on the $4^{\text {th }}$ National Literature Congress, further promoting the implementation of "double hundred" policy in China, and quickening the course of Chinese culture getting rid of political movement. These policies and new thoughts resulted in great development of Chinese culture. At the same time, numerous excellent musicians (like Li Guyi and Xu Xiaoming) and films and television programs (like Shaolin Temple and The Thrill of Life) emerged one after another. This is the beginning of Chinese mass culture's development.

With rapid development of mass culture, Report on Enhancing Urban Mass Culture Works passed in 1985. In the Report, it is pointed out that culture should develop toward the diversified orientation, greatly mobilizing the initiative of cultural workers. Moreover, the people's recreational activities also gradually developed in this period of time. With popularization of "karaoke", discotheque also emerged accordingly. There were diversified types of recreational activities for urban people. To construct into a powerful cultural country, encourage culture to get closer to the public and practical life, and serve the public, the $18^{\text {th }}$ National Congress proposed to "carry forward academic democracy \& artistic democracy, and provide a stage for development of mass culture”. Loose cultural policy provides a good opportunity for development of mass culture. Determination of market economic system also provides a good economic foundation for cultural development, which promotes development of Chinese mass culture together with openness and development of the people's thought. The current mass culture is a based on industrial age. On the one hand, products enter the people's life. On the other hand, products can be massively reproduced. Although the feature of commodity still exists, mass culture is still accepted and appreciated by wide audiences. With improvement to the people's economic level and continuous development of the people's open thought, Chinese mass culture will become more and more prosperous in the future life by abandoning its development disadvantages.

\section{Relationship between popular music and mass culture}

\section{Music is closely associated with culture.}

Ye Wenling, a famous writer, used to say that “music and poem are naturally consistent art”. In ancient times, men of literature and writing were drinking and singing at river bank. They would begin to compose a poem or draw a picture when they were quite interested in something. This is the best example for integration between music and culture.

\section{Music promotes cultural transmission.}

As an effective communication pattern, music has amazing infection and creativity. With Little Apple as an example, it is quite popular in China. More importantly, it was also performed in the street in foreign countries. This is just manifestation of music promoting culture. It quickened cultural transmission speed, expanded the scope of cultural transmission, and further promoted the external communication function of Chinese culture.

\section{Culture is pregnant with music.}

As an important symbol of culture, music was generated because of culture. For example, the formation of popular music was promoted due to development of the industrial revolution and impact between black culture and traditional culture. Thus, it is not strange for the case Chinese style is added into Chinese music with a long history of Chinese traditional culture. 


\section{Music adds communication routes and channels to culture.}

Popular music is taught orally, which not only gives expression to the people's emotion but also quickens cultural transmission. Cultural transmission is converted from a written form to an oral and vertical form. It becomes more infective and more influential.

\section{Musical and cultural works play a role in relieving and communicating emotions.}

Both musical and cultural works are good media for cultivation of personal taste and interest. When a person is in bad mood, he can listen to some easy music or watch some funny movies. When he is sleepless, he can listen to some easy music or read some literary works. All these roles are played by musical and cultural works in our life. They play a role in body relief and emotional communication.

\section{Important role of popular music for mass culture}

Popular music and culture are mutually integrated and influenced. Popular music mainly has the following influences on mass culture:

\section{Popular music promotes popularity of mass culture}

To meet its commercial demands, therefore, mass culture needs to cater for the public's demands and meet popular psychology with a low profile. This is required by popularity of mass culture. However, popular music properly captured mass demands. To promote its wide communication, popular music is closer to the people's daily life in terms of content. Therefore, popular music can transmit mass culture with approaches loved by most people, and promote popularity of mass culture at the same time.

\section{Popular music can promote interestingness of mass culture}

To attract the public, culture cannot only rely on its popularity. Instead, it should be interesting as well. However, popular music has diversified categories. Rooted in mass interests, popular music is the best type of music used to deploy the mass interest. With On the Moon as an example, its words are not literary enough, but words closer to common people can move the people in a better way. This song successfully deploys the mass interest, and further promotes communication of mass culture.

\section{Popular music promotes fashion of mass culture}

Popular music got continuous development by conforming to the times. It is featured by rapid variation frequency, meeting the mass demands. At present, popular music emphasizes fashion, meeting the people's pursuit for fashion. Moreover, popular music itself is one of components of mass culture. Therefore, pursuit of popular music for fashion further promotes fashion of mass culture.

\section{Popular music enriches connotation and mode of mass culture}

As one of mass culture communication modes, popular music is popular among the whole mass group. At the same time, it also absorbs various cultural demands and internal patterns of the mass. Diversified patterns of popular music enrich the connotation of mass culture. Moreover, mass culture communication is developed from a written and word form to the mode of movie, resulting in richer connotations of mass culture and making it to be communicated in a wider scope.

\section{Popular music keeps continuously developing on the basis of mass culture}

On the one hand, popular music promotes mass culture communication. On the other hand, variation in mass culture also changes popular music accordingly. In the period of industrial revolution, popular music emphasized the pursuit for scientific and technological content. Nowadays, however, mass culture pursues for easy and happy contents. This is the expression of influence from external mass culture on popular music. 


\section{Summary}

To sum up, mass culture is a cultural product of the whole society. Popular music is one of representatives of mass culture. Popular music communicated thoughts and emotions of the singers, and delivered overall demands and desires of the whole society. At the same time, popular music is also a product rooted in the basis of mass culture in the society, for instance, nationality of black music in western music and popular music with Chinese style. All these factors indicate building of culture for music. The public's resonance is aroused through popular music. Then, the function of cultural education is represented. This is the communication function of music for culture. Development of mass culture influences pattern and communication mode of popular music. However, communication of popular music also further promotes the public's understanding and absorption of culture. This is the expression of interaction between popular music and mass culture. At the same time, this is of great importance for our study and development of mass culture in the future.

\section{Acknowledgments}

This paper is the phased research achievement of Hainan Federation of Social Science Circles Research on Hainan Folk Song Development and Value (HNSK (YB) 15-104).

\section{References}

[1] Zhang Xue, Popular Music of Contemporary China under the Background of Mass Culture, Social Culture, 2010 (1): 11-13;

[2] Wang Siqi, Concept and Cultural Characteristics of Popular Music, Mass Culture, 2013 (2): 11-15;

[3] Xiang Xiaogang, Discussion on Hong Kong and Taiwan Popular Music in New Period and Its Influence on Mainland Popular Music, Music Weekly, 2013 (4): 6-16;

[4] Xu Xiwen and Xie Jianming, Discussion on Art World of Popular Music in Contemporary China, Journal of Shandong University, 2014 (4): 15-30;

[5] Wang Li, Discussion on influence of Popular Music on Culture of the Mainland, Macao, Taiwan and Hong Kong and Its Development Strategy, Journal of West Anhui University, 2013 (4): 23-34 